\title{
四川柏木人工林林下植被生物量与林分结构的关系
}

\author{
金艳强 ${ }^{1,2}$ 包维楷 $1, *$ \\ (1. 中国科学院成都生物研究所,山地生态恢复与生物资源利用重点实验室, 成都 610041 ; \\ 2. 中国科学院大学, 北京 100049)
}

\begin{abstract}
摘要: 森林结构与林下植被生物量的关系是森林持续经营与森林碳计量监测的科学基础,但一直缺乏必要的研究。以四川柏木 (Cupressus funebris) 人工林为研究对象, 揭示林下植被生物量 $\left(W_{\mathrm{u}}\right)$ 、灌木生物量 $\left(W_{\mathrm{s}}\right)$ 和草本生物量 $\left(W_{\mathrm{h}}\right)$ 与林分结构的关系, 并 试图构建区域性林下植被生物量估测的混合模型。结果表明:（1) 乔、灌、草群体共 12 个结构因子中,灌木群体的平均基径 $\left(D_{\mathrm{s}}\right)$ 、盖度 $\left(C_{\mathrm{s}}\right)$ 、高度 $\left(H_{\mathrm{s}}\right)$ 、体积 $\left(V_{\mathrm{s}}\right)$ 与林下植被生物量关系更紧密, 在林下植被生物量模型构建中更有效; (2) 多模型拟合 与比较表明, 柏木林 $W_{\mathrm{s}}$ 最佳估算模型为 $W_{\mathrm{s}}=0.0005 V_{\mathrm{s}}^{1.0411}\left(R_{\mathrm{a}}^{2}=0.762, P<0.001, n=40\right)$, 而 $W_{\mathrm{u}}$ 的最佳估算模型为 $\ln W_{\mathrm{u}}=0.0158 H_{\mathrm{s}}$ $+0.0111 C_{\mathrm{s}}-0.5358\left(R_{\mathrm{a}}^{2}=0.695, P<0.001, n=40\right)$, 但对于 $W_{\mathrm{h}}$ 未能获得较为理想的估算模型 $\left(R_{\mathrm{a}}^{2}<0.410, P<0.01, n=40\right) ;(3)$ 林 分密度 $\left(D_{\mathrm{u}}\right)$ 整合进人多元线性模型提高了林下植被生物量的估测精度, $\ln W_{\mathrm{u}}=a+b D_{\mathrm{u}}+c H_{\mathrm{s}}+d C_{\mathrm{s}}\left(R_{\mathrm{a}}^{2}=0.721, P<0.001, n=40\right)$ 。 研究为区域性林下生物量估测模型构建提供了新论据。
\end{abstract}

关键词:林下植被;生物量;生物量模型;林分结构;柏木林

\section{Relationships of the understory biomass with stand structure of the Sichuan cypress plantation forests across Sichuan Basin, China}

JIN Yanqiang ${ }^{1,2}$, BAO Weikai ${ }^{1, *}$

1 Key Laboratory of Mountain Ecological Restoration and Bioresource Utilization, Chengdu Institute of Biology, Chinese Academy of Sciences, Chengdu 610041, China

2 University of Chinese Academy of Sciences, Beijing 100049, China

\begin{abstract}
The understory biomass $\left(W_{\mathrm{u}}\right)$ and its relationships with stand structure are paramount important for sustainable management and carbon accounting for forest ecosystem, but until now it remains poorly understood. Therefore we selected Sichuan cypress (Cupressus funebris) plantation forests across Sichuan basin, southwestern China, to explore the correlations of $W_{\mathrm{u}}$ with stand structure and to establish the regional estimation models for $W_{\mathrm{u}}$ and its components- Shrub biomass $\left(W_{\mathrm{s}}\right)$ and herbaceous biomass $\left(W_{\mathrm{h}}\right)$. We tried to answer two questions: which structural parameters would relate closely to the $W_{\mathrm{u}}, W_{\mathrm{s}}$ and $W_{\mathrm{h}}$ and therefore can be integrated into the biomass estimation models, respectively, and whether the fit estimation models by integrating the overstory parameter could be better to predict $W_{\mathrm{u}}$ across the region. We employed plot methods to survey the stand structure including tree, shrub and herbaceous layers and the $W_{\mathrm{u}}, W_{\mathrm{s}}$ and $W_{\mathrm{h}}$ of below- and above-ground on fourteen Sichuan cypress forests from 12 counties in Sichuan basin. Pearson correlation analysis was applied to explore the relationships of the $W_{\mathrm{u}}, W_{\mathrm{s}}$ and $W_{\mathrm{h}}$ with all 12 structural parameters and five models were selected to simulate and screen the fitted biomass estimation equations. Our data displayed that the $W_{\mathrm{u}}$ and $W_{\mathrm{s}}$ had significant correlations with the percentage cover $\left(C_{\mathrm{s}}\right)$, average height $\left(H_{\mathrm{s}}\right)$ and the projected volume $\left(V_{\mathrm{s}}=C_{\mathrm{s}} \times H_{\mathrm{s}}\right)$ of shrubs, it was closer than that with other structural parameters including stand density $\left(D_{\mathrm{u}}\right)$. Among all fitting equations, the power equation was the best one to estimate the shrub biomass: $W_{\mathrm{s}}=0.0005 V_{\mathrm{s}}^{1.0411}\left(R_{\mathrm{a}}^{2}=0.762, P<0.001, n=40\right)$, and the multiple linear regression model to the understory biomass: $\ln W_{\mathrm{u}}=0.0158 H_{\mathrm{s}}+0.0111 C_{\mathrm{s}}-0.5358\left(R_{\mathrm{a}}^{2}=0.695, P<0.001\right.$,
\end{abstract}

基金项目: 中国科学院战略性先导科技专项(XDA0505020407)

收稿日期: 2013-01-21; 网络出版日期:2014-03-11

* 通讯作者 Corresponding author.E-mail: baowk@ cib.ac.cn 
$n=40)$. We did not find suitable fitting model to estimate the herbaceous biomass across the Sichuan cypress plantation due to the adjusted coefficient no more than $0.410\left(R_{\mathrm{a}}^{2}<0.410, P<0.01, n=40\right)$. An important finding was that integrating $D_{\mathrm{u}}$ into the multiple linear regression model could improve the estimation accuracy for $W_{\mathrm{u}}$ across the region $\left(\ln W_{\mathrm{u}}=a+b D_{\mathrm{u}}+\right.$ $\left.c H_{\mathrm{s}}+d C_{\mathrm{s}}, R_{\mathrm{a}}^{2}=0.721, P<0.001, n=40\right)$. We concluded that $W_{\mathrm{u}}$ is important and can be better predicted by $C_{\mathrm{s}}, H_{\mathrm{s}}$ or $V_{\mathrm{s}}$ with $D_{\mathrm{u}}$ for the Sichuan cypress plantation forests across Sichuan basin, providing new insight to develop the understory biomass estimation models for the regional forest carbon accounting system.

Key Words : understory; biomass; regression model; forest structure; Cupressus funebris

林下植被一般指高度小于 $3 \mathrm{~m}$ 的林下植物层 片, 主要由灌木、乔木幼苗以及草本组成, 是森林的 必要组分, 在保育乡土动植物区系和生物多样性、为 其它动物提供生境和食物来源、养分循环、促进林地 生产力的长期持续性及促进森林更新和演替等方面 发挥着重要作用 ${ }^{[1-2]}$ 。因此,林下植被一直是森林持 续经营、生物多样性保护和森林功能维持的关 键 ${ }^{[2-4]}$ 。然而几十年来对森林生物量与生产力的研 究主要聚焦于林木, 对林下植被生物量与生产力的 研究缺乏重视, 与林分结构的关系认知严重不足 ${ }^{[5]}$ 。 林下植被总生物量虽然不高, 但其细根生物量比例 较高 ${ }^{[6]}$, 作为森林的一个活跃的养分库,林下植被总 生物量在森林养分循环以及林地生产力维持中起到 关键作用。

林下植被发育与森林冠层结构紧密相关 ${ }^{[7]}$, 揭 示林下植被生物量与森林结构的关系是认识森林结 构与功能动态变化的基础。理论上,林下植被的生 物量不仅受自身结构 (盖度、基径、高度、体积 (盖度 与高的乘积) 等) 直接影响 ${ }^{[8-9]}$, 更受到乔木冠层的 复杂制约。虽有一些研究揭示了灌丛或草地的生物 量与群落结构性状的关系 ${ }^{[10-11]}$, 但林下植被的生物 量与其结构性状的关系缺乏必要研究; 而林下植被 生物量与冠层结构的关系虽有少量研究, 但结论并 不统一。一些研究发现林下植被生物量受林分冠层 影响严重 ${ }^{[12-14]}$, 而另一些研究表明林下植被生物量 的变化与林分密度没有明显相关关系 ${ }^{[15-16]}$ 。因此, 进一步明确林下植被生物量与林分结构的关系是必 要的。对柏木林的研究主要集中在柏木林的生态效 应方面,其中柏木结构与林分生物量有不少研究,但 大多数是调查林分生物量现状, 涉及与林分结构因 子(密度、胸高直径与高度) 的关系探讨 ${ }^{[17-20]}$ 。已有 研究发现, 柏木人工林林下植被生物量占到群落总 生物量的 $3.7 \%-23.6 \%$, 不容忽视。而针对柏
木人工林林下植被生物量与林分结构的关系至今缺 乏研究。

另外,估测林下植被生物量是森林功能及森林 碳清算计量不可缺少的内容。传统而广泛采用的林 下植被生物量测定方法是直接全收获法, 很少有研 究通过模型来估算林下植被生物量 ${ }^{[17]}$, 在已有的少 数林下植被生物量估测研究中, 主要聚焦单优势灌 木种群生物量估算模型 (Species-specific models) 的 研究 ${ }^{[22-24]}$ 。黎燕琼等 ${ }^{[25]}$ 研究过柏木人工林林下优 势灌木黄荆 (Vitex negundo) 的基径、均高等结构参数 与其生物量的关系, 采用基径和均高发展了黄荆生 物量的单种估算模型, 获得了较好的估算效果 $\left(R^{2}=\right.$ $0.906)$ 。然而, 柏木人工林林下植被物种组成丰富, 向成华等 ${ }^{[26]}$ 的调查发现柏木人工纯林灌木层物种 数为 15 , 草本层 28 种。而且柏木人工林林下植被优 势种地位也并不总是突出 ${ }^{[20,27]}$, 尤其是在中龄林阶 段或密林状态。显然使用优势种单种模型不适用于 估算区域林下植被生物量。针对每个种建立异速生 长方程的工作量较大, 且难以实现。因此, 对区域性 广泛分布的柏木林下植被生物量估算迫切需要发展 基于林下植物总体易测结构参数的生物量估测混合 模型 (Mixed-species models)，以提高估算效率。

因此,本文选取四川盆地柏木人工林展开调查 研究, 主要目的是揭示林分结构参数与林下植被生 物量关系, 以及使用林分结构参数构建区域林下植 被生物量的估测模型。研究结果可为四川柏木生物 量估测以及碳计量体系建设提供直接的模型和方法 依据。

\section{1 研究区概况}

柏木 (Cupressus funebris) 是 20 世纪 60 年代以来 四川盆地集体林区荒山绿化造林的主要树种, 目前 柏木人工林成为川中丘陵区的优势森林类型之 


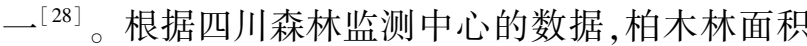
从 1979 年的 49.4 万 $\mathrm{hm}^{2}$ 已增加到 2007 年的 145.2 万 $\mathrm{hm}^{2}$,在长江上游防护林工程体系建设中发展迅 速,以四川、湖北西部、贵州栽培最多。研究区域覆 盖广元、巴中、绵阳、南充、遂宁等地市的 12 个县区， 东经 $103^{\circ} 30^{\prime}-109^{\circ} 30^{\prime}$, 北纬 $28^{\circ} 40^{\prime}-32^{\circ} 40^{\prime}$ 之间, 海拔 350-700 m, 地貌以丘陵为主,是 20 世纪 80 年 代长江上游防护林建设中柏木造林的重点区域。该 区属亚热带湿润季风气候,四季分明,年降水量一般 为 $1000-1200 \mathrm{~mm}$, 年均温 $16-18{ }^{\circ} \mathrm{C}$, 全年日照时 数 1000-1400 h。土壤以紫色土为主, 土层浅薄, 肥 力不高, 因此发育的柏木林生产力 (生物量) 不 高 ${ }^{[20]}$, 群落结构比较简单, 林下植被成丛明显。林 下主要灌木种类主要有黄荆、马桑 (Coriaria nepalensis)、铁仔(Myrsine africana)、火棘(Pyracantha fortuneana) 等, 而草本主要有白茅（Imperata cylindrica)、莎草 (Cyrerus microiria)、菍草 (Arthraxon hispidus $)$ 等 ${ }^{[20,27]}$ 。

\section{2 研究方法}

\section{1 样方调查}

2011 年在研究区针对柏木人工林设置了 14 个 面积为 $1000 \mathrm{~m}^{2}(20 \mathrm{~m} \times 50 \mathrm{~m})$ 的典型样地, 其中一块
样地受地形限制, 样地面积调整为 $800 \mathrm{~m}^{2}(20 \mathrm{~m} \times 40$ $\mathrm{m})$, 然后把样地划分成 $100 \mathrm{~m}^{2}(10 \mathrm{~m} \times 10 \mathrm{~m})$ 的乔木 样方, 分别记录每一个样方的郁闭度 $C_{\mathrm{t}}$, 然后进行每 木检尺, 测定大于 $3 \mathrm{~m}$ 的乔木层每株的树高、胸径、 冠幅。在样地中机械布点设置 3 个 $2 \mathrm{~m} \times 2 \mathrm{~m}$ 的灌木 样方, 布设于乔木亚样方。灌木样方调查了灌木物 种组成, 测定了总盖度, 然后分种测定每一灌木群体 的平均基径、平均高度后, 将样方内所有灌木全部收 获后, 分枝茎、叶、根三部分就地称鲜重, 然后各部分 分别取约 $300 \mathrm{~g}$ 混合样带回实验室测定含水率, 以 便将鲜生物量换算为干重。在 3 个灌木样方的右上 角,分别设置 1 个 $1 \mathrm{~m} \times 1 \mathrm{~m}$ 的草本样方, 估测总盖 度后记录种类组成, 然后分种测定各草群平均高度; 然后将样方内所有草本植物全部收获, 分地上部分 和地下部分称鲜重, 然后取约 $300 \mathrm{~g}$ 混合样带回实 验室测定含水率。把灌木和草本样品都在 $70{ }^{\circ} \mathrm{C}$ 烘 3 天后测定含水率, 以含水率将灌木和草本各样方生 物量鲜重按成分 (叶、枝茎、根,地上、地下) 换算成干 重生物量 $\left(\mathrm{t} / \mathrm{hm}^{2}\right)$ 。野外调查了 14 块样地, 样地基 本概况见表 1 , 获取乔木样方的乔木层结构参数以及 相应的灌草样方数据各 42 个, 由于其中 2 个样方无 灌草而没纳入模型构建, 因此本文用 40 个样方数据 进行分析。

表 1 四川柏木人工林样地调查基本概况

Table 1 Stand situation for the Cupressus funebris plantation forests from Sichuan

\begin{tabular}{|c|c|c|c|c|c|c|c|c|c|}
\hline $\begin{array}{l}\text { 样地 } \\
\text { Site }\end{array}$ & $\begin{array}{c}\text { 经度 } \\
\text { Latitude }\end{array}$ & $\begin{array}{c}\text { 纬度 } \\
\text { Longitude }\end{array}$ & $\begin{array}{l}\text { 海拔/m } \\
\text { Altitude }\end{array}$ & $\begin{array}{l}\text { 坡向 } \\
\text { Aspect }\end{array}$ & $\begin{array}{c}\text { 坡度/ }\left(^{\circ}\right) \\
\text { Slope }\end{array}$ & $\begin{array}{c}\text { 坡位 } \\
\text { Slope position }\end{array}$ & $\begin{array}{c}\text { 样地 } \\
\text { 面积 } / \mathrm{m}^{2} \\
\text { Stand area }\end{array}$ & $\begin{array}{l}\text { 郁闭度 } \\
\text { Corerage }\end{array}$ & $\begin{array}{c}\text { 林分密度 } \\
\text { Density／ } \\
\left(\text { 株/ } \mathrm{hm}^{2} \text { ) }\right.\end{array}$ \\
\hline $\mathrm{P} 1$ & $105^{\circ} 17.69^{\prime}$ & $31^{\circ} 22.16^{\prime}$ & 525 & $\mathrm{ES} 10^{\circ}$ & 27 & 中 & 1000 & 0.6 & 3470 \\
\hline $\mathrm{P} 2$ & $105^{\circ} 25.21^{\prime}$ & $31^{\circ} 13.48^{\prime}$ & 540 & $\mathrm{NW} 20^{\circ}$ & 29 & 中 & 1000 & 0.7 & 4430 \\
\hline P3 & $105^{\circ} 10.10^{\prime}$ & $31^{\circ} 04.85^{\prime}$ & 436 & $\mathrm{ES} 40^{\circ}$ & 29 & 中 & 1000 & 0.6 & 3110 \\
\hline $\mathrm{P} 4$ & $105^{\circ} 22.57^{\prime}$ & $30^{\circ} 47.51^{\prime}$ & 396 & $\mathrm{SW} 20^{\circ}$ & 38 & 上 & 1000 & 0.6 & 2530 \\
\hline P5 & $105^{\circ} 37.64^{\prime}$ & $30^{\circ} 48.45^{\prime}$ & 345 & $\mathrm{NE} 15^{\circ}$ & 41 & 下 & 1000 & 0.7 & 990 \\
\hline P6 & $105^{\circ} 22.64^{\prime}$ & $30^{\circ} 38.89^{\prime}$ & 359 & NW5 ${ }^{\circ}$ & 52 & 中 & 1000 & 0.65 & 1370 \\
\hline P7 & $105^{\circ} 40.43^{\prime}$ & $31^{\circ} 30.74^{\prime}$ & 600 & $\mathrm{SW} 29^{\circ}$ & 44 & 中 & 1000 & 0.6 & 1770 \\
\hline P8 & $107^{\circ} 40.16^{\prime}$ & $32^{\circ} 03.76^{\prime}$ & 790 & $\mathrm{SE} 20^{\circ}$ & 40 & 下 & 1000 & 0.4 & 960 \\
\hline P9 & $107^{\circ} 04.37^{\prime}$ & $31^{\circ} 55.76^{\prime}$ & 660 & $\mathrm{SW}^{\circ}$ & 39 & 中 & 800 & 0.9 & 3050 \\
\hline P10 & $105^{\circ} 40.49^{\prime}$ & $31^{\circ} 35.05^{\prime}$ & 440 & $\mathrm{NW} 39^{\circ}$ & 31 & 上 & 1000 & 0.85 & 2460 \\
\hline P11 & $106^{\circ} 46.05^{\prime}$ & $31^{\circ} 30.08^{\prime}$ & 595 & S & 49 & 中 & 1000 & 0.7 & 1860 \\
\hline P12 & $106^{\circ} 03.21^{\prime}$ & $31^{\circ} 34.90^{\prime}$ & 488 & $\mathrm{NW70} 0^{\circ}$ & 54 & 上 & 1000 & 0.65 & 3490 \\
\hline P13 & $107^{\circ} 01.20^{\prime}$ & $31^{\circ} 25.57^{\prime}$ & 500 & $\mathrm{SW} 33^{\circ}$ & 43 & 中 & 1000 & 0.5 & 1650 \\
\hline P14 & $106^{\circ} 53.87^{\prime}$ & $31^{\circ} 38.63^{\prime}$ & 540 & $\mathrm{SE} 47^{\circ}$ & 51 & 中 & 1000 & 0.78 & 690 \\
\hline
\end{tabular}

2.2 数据整理与统计分析

根据野外调查获得各样方中林下灌木总盖度 $C_{\mathrm{s}}$
（\%）、平均高度 $H_{\mathrm{s}}(\mathrm{cm})$, 计算灌木群体平均基径 $D$ $(\mathrm{cm})$ 及体积 $V_{\mathrm{s}}\left(V_{\mathrm{s}}=C_{\mathrm{s}} \times H_{\mathrm{s}}\right)^{[29]}$; 根据草本群体的均 
高 $H_{\mathrm{h}}(\mathrm{cm})$ 与盖度 $C_{\mathrm{h}}(\%)$, 然后计算出草群体积 $V_{\mathrm{h}}$ $\left(V_{\mathrm{h}}=C_{\mathrm{h}} \times H_{\mathrm{h}}\right)$; 根据含水率和鲜重, 计算获得每个小 样方中的各类群以及总体各部分的干重, 然后换算 林下植被各部分生物量 $\left(\mathrm{t} / \mathrm{hm}^{2}\right)$ : 林下植被总生物量 $W_{\mathrm{u}}$ 、林下灌木生物量 $W_{\mathrm{s}}$ 及林下草本生物量 $W_{\mathrm{h}}$ 。根 据乔木样方实测值胸径, 计算平均胸径 $D_{\mathrm{a}}(\mathrm{cm})$ 、平 均高度 $H_{\mathrm{t}}(\mathrm{m})$ 以及林分密度 $D_{\mathrm{u}}\left(\right.$ 株 $\left./ \mathrm{hm}^{2}\right)$ 。最后按 圆柱计算出胸高断面积 $B_{\mathrm{t}}\left(\mathrm{m}^{2}\right)$ 。各参数基本范围
见表 2 。

使用 Shapiro-Wilk 指数对林下植被生物量参数 $\left(W_{\mathrm{u}} 、 W_{\mathrm{s}} 、 W_{\mathrm{h}}\right)$ 以及林分结构参数 $\left(H_{\mathrm{s}} 、 C_{\mathrm{s}} 、 V_{\mathrm{s}} 、 H_{\mathrm{h}} 、 C_{\mathrm{h}} 、\right.$ $\left.V_{\mathrm{h}} 、 C_{\mathrm{t}} 、 B_{\mathrm{t}} 、 D_{\mathrm{a}} 、 D_{\mathrm{u}} 、 H_{\mathrm{t}}\right)$ 进行正态性检验, 对不满足正 态性检验的变量进行自然对数转换。然后使用 Pearson 相关分析去揭示林下植被生物量与林分结 构的关系, 根据相关系数判断紧密程度。

表 2 四川盆地柏木林冠层和下层植被基本结构参数统计

Table 2 Descriptive statistics on some structural parameters of understory and overstory for the Cupressus funebris plantation forests from Sichuan

\begin{tabular}{lccccccccccc}
\hline & $\begin{array}{c}H_{\mathrm{s}} / \\
\mathrm{cm}\end{array}$ & $\begin{array}{c}D_{\mathrm{s}} / \\
\mathrm{cm}\end{array}$ & $\begin{array}{c}C_{\mathrm{s}} / \\
\%\end{array}$ & $\begin{array}{c}H_{\mathrm{h}} / \\
\mathrm{cm}\end{array}$ & $\begin{array}{c}C_{\mathrm{h}} / \\
\%\end{array}$ & $\begin{array}{c}C_{\mathrm{u}} / \\
\%\end{array}$ & $C_{\mathrm{t}}$ & $\begin{array}{c}D_{\mathrm{u}} / \\
\left(\text { 株 } / \mathrm{hm}^{2}\right)\end{array}$ & $\begin{array}{c}B_{\mathrm{r}} / \\
\mathrm{m}^{2}\end{array}$ & $\begin{array}{c}D_{\mathrm{a}} / \\
\mathrm{cm}\end{array}$ & $\begin{array}{c}H_{\mathrm{t}} / \\
\mathrm{m}\end{array}$ \\
\hline 样方数 N & 40 & 40 & 40 & 40 & 40 & 40 & 40 & 40 & 40 & 40 & 40 \\
均值 Mean & 82 & 0.91 & 29.4 & 20.8 & 52 & 84.6 & 0.6 & 1995.0 & 0.136 & 9.1 & 8 \\
标准误 SE & 5.7 & 0.14 & 3.5 & 1 & 4.4 & 1.9 & 0 & 208.3 & 0.018 & 0.6 & 0.4 \\
最小值 Minimum & 31.8 & 0.14 & 0.3 & 8 & 9 & 57 & 0.2 & 300.0 & 0.003 & 3.2 & 3.7 \\
最大值 Maximum & 176 & 4.97 & 83 & 34 & 100 & 99 & 0.9 & 5400.0 & 0.677 & 21.4 & 14.7 \\
\hline
\end{tabular}

$H_{\mathrm{s}}$ : 灌木均高 average shrub height; $D_{\mathrm{s}}$ : 灌木平均基径 average diameter for shrub; $C_{\mathrm{s}}$ : 灌木盖度 shrub cover; $H_{\mathrm{h}}$ : 草本均高 average herbaceous height; $C_{\mathrm{h}}$ : 草本盖度 herbaceous cover; $C_{\mathrm{u}}$ : 林下植被总盖度 understory cover; $C_{\mathrm{t}}$ : 郁闭度 canopy; $D_{\mathrm{u}}$ : 林分密度 stand density; $B_{\mathrm{t}}$ : 总胸高断面积 total basal area; $D_{\mathrm{a}}$ : 平均胸径 average diameter at basal height; $H_{\mathrm{t}}$ : 乔木均高 average height for overstory

基于前面的相关分析, 挑选与林下植被生物量 $\left(W_{\mathrm{u}} 、 W_{\mathrm{s}} 、 W_{\mathrm{h}}\right)$ 关系紧密的结构参数作为预测变量, 分 别对 $W_{\mathrm{u}} 、 W_{\mathrm{s}} 、 W_{\mathrm{h}}$ 进行多种模型的拟合。根据已有研 究中对林下植被生物量与形态结构特性关系结 果 ${ }^{[30]}$, 选用的模型方程形式有

$$
\begin{gathered}
W=a+b X \\
W=a+b X_{1}+c X_{2} \\
W=a+b X_{1}+c X_{2}+d X_{3} \\
W=a+b X_{1}+c X_{2}^{2} \\
W=a X^{b}
\end{gathered}
$$

式中, $X 、 X_{1} 、 X_{2} 、 X_{3}$ 即为模型预测变量, $a 、 b 、 c$ 为常系 数。在拟合中,如模型有 2 个参数时就选取任意 2 个预测变量,如 3 个参数时即随机选择 3 个预测变 量进行拟合,使用 $F$ 检验对其进行模型显著性检验。 采用调整的决定系数 $\left(R_{\mathrm{a}}^{2}\right)$ 和模型估计误差 (SEE) 两个指标来评价显著性模型的优劣, $R_{\mathrm{a}}^{2}$ 较大, 且 SEE 较小的模型作为最佳估算模型 ${ }^{[31]}$ 。

为了增强模型在空间的延展性, 选取与灌草样 方相对应亚样方的林分结构性状因子包括 $D_{\mathrm{u}}$ 、郁闭 度、总胸高断面积作为变量, 采用逐步回归方法对林
下植被生物量进行模型拟合。使用 AIC 值( Akaike Information Criterion) 作为模型选取的标准, 取 AIC 值最低的模型作为最佳拟合模型 ${ }^{[32]}$ 。AIC 值计算通 过方程:

$$
\mathrm{AIC}=2 k-n \times \ln (\mathrm{RSS} / n)
$$

式中, $k$ 是参数数量, RSS 为剩余平方和, $n$ 为样本 数 40 。

数据分析和模型的拟合检验均使用 R.2.15.0 软 件 $^{[33]}$ 完成。

\section{3 结果与分析}

3.1 林下植被总生物量与林分结构的关系

柏木 $W_{\mathrm{u}}$ 与林分各层片结构参数的关系差异较 大(图 1)。 $W_{\mathrm{u}}$ 与灌木 $D_{\mathrm{s}}(R=0.493, P<0.001), C_{\mathrm{s}}$ $(R=0.570, P<0.001)$ 和 $V_{\mathrm{s}}(R=0.725, P<0.001)$ 的关 系紧密 (图 1), 与 $H_{\mathrm{s}}(R=0.799, P<0.001)$ 的关系最 为紧密; 而 $W_{\mathrm{u}}$ 与 $V_{\mathrm{h}}(R=0.333, P=0.036)$ 的关系紧 密, 与草本其它的结构参数 $C_{\mathrm{h}} 、 H_{\mathrm{h}}$ 和 $V_{\mathrm{h}}$ 的关系, 以及 与乔木层的 $H_{\mathrm{t}} 、 C_{\mathrm{t}} 、 D_{\mathrm{t}} 、 B_{\mathrm{t}} 、 D_{\mathrm{a}}$ 这 5 个结构参数间的相 关关系都不显著 $(P>0.05)$ 。 

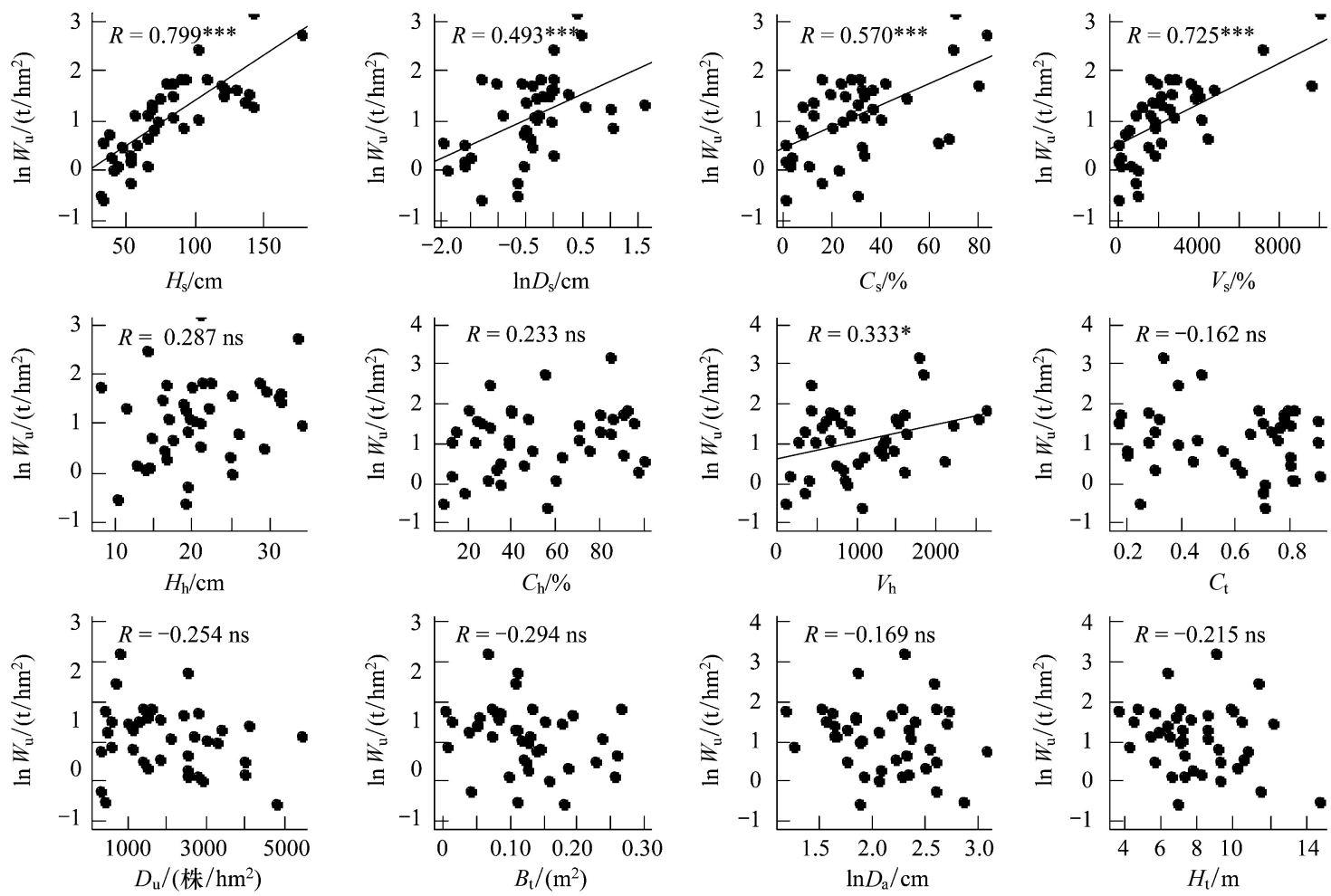

图 1 四川柏木林下植被生物量 $\left(W_{u}\right)$ 与林分结构的关系

Fig.1 Pearson's correlations between biomass with structural parameters of overstory and understory in the Cupressus funebris plantation forests from Sichuan Basin

$H_{\mathrm{s}}$, 灌木均高 average shrub height; $D_{\mathrm{s}}$, 灌木平均基径 average diameter for shrub; $C_{\mathrm{s}}$, 灌木盖度 shrub cover; $V_{\mathrm{s}}$, 灌木体积 $\left(V_{\mathrm{s}}=H_{\mathrm{s}} \times C_{\mathrm{s}}\right)$ shrub volume $\left(V_{\mathrm{s}}=H_{\mathrm{s}} \times C_{\mathrm{s}}\right) ; H_{\mathrm{h}}$, 草本均高 average herbaceous height; $C_{\mathrm{h}}$, 草本盖度 herbaceous cover; $V_{\mathrm{h}}$, 草本体积 $\left(V_{\mathrm{h}}=H_{\mathrm{h}} \times C_{\mathrm{h}}\right)$ herbaceous volume $\left(V_{\mathrm{h}}\right.$ $\left.=H_{\mathrm{h}} \times C_{\mathrm{h}}\right) ; C_{\mathrm{t}}$, 郁闭度 canopy; $D_{\mathrm{u}}$, 林分密度 stand density ; $B_{\mathrm{t}}$, 胸高断面积 basal area $; D_{\mathrm{a}}$, 平均胸径 average diameter at basal height; $H_{\mathrm{t}}$, 乔木均高 average height for overstory; $R$, 相关系数 correlation coefficient;ns, $P>0.05 ; *, P<0.05 ; * *, P<0.01 ; * * *, P<0.001$

\section{2 林下灌木生物量与林分结构的关系}

柏木林下灌木 $W_{\mathrm{s}}$ 与自身结构参数 $H_{\mathrm{s}}(R=$ $0.725, P<0.001) 、 D_{\mathrm{s}}(R=0.612, P<0.001) 、 C_{\mathrm{s}}(R=$ $0.593, P<0.001)$ 和 $V_{\mathrm{s}}(R=0.637, P<0.001)$ 的关系也 较为紧密 (图 2); $W_{\mathrm{s}}$ 与草本的 $C_{\mathrm{h}} 、 H_{\mathrm{h}}$ 和 $V_{\mathrm{h}}$ 的关系都 不显著 $(P>0.05)$; 然而 $W_{\mathrm{s}}$ 与林分结构参数中的 $B_{\mathrm{t}}$ 有显著负相关关系 $(R=-0.516, P<0.001)$, 而与 $H_{\mathrm{t}}$ 、 $C_{\mathrm{t}} 、 D_{\mathrm{t}}$ 和 $D_{\mathrm{a}}$ 的关系都不显著 $(P>0.05)$ 。

\section{3 林下草本生物量与林分结构的关系}

林下草本生物量 $W_{\mathrm{h}}$ 与自身的 $C_{\mathrm{h}}$ 的关系显著 $(R=0.377, P=0.016$; 图 3$)$, 而 $V_{\mathrm{h}}$ 的关系更紧密 $(R=$ $0.464, P=0.003)$, 但与 $H_{\mathrm{h}}$ 之间没有显著关系 $(P>$ $0.05)$ 。而 $W_{\mathrm{h}}$ 与灌木结构参数 $H_{\mathrm{s}}(R=0.444, P=$ $0.004)$ 和 $V_{\mathrm{s}}(R=0.367, P=0.02)$ 关系都较为紧密, 但与灌木的 $D_{\mathrm{s}}$ 和 $C_{\mathrm{s}}$ 没有显著关系 $(P>0.05)$ 。 $W_{\mathrm{h}}$ 与乔木层结构参数 $\left(H_{\mathrm{t}} 、 C_{\mathrm{t}} 、 B_{\mathrm{t}} 、 D_{\mathrm{t}}\right.$ 和 $\left.D_{\mathrm{a}}\right)$ 间的关系都 不显著 $(P>0.05)$ 。
3.4 林下植被生物量混合模型

如前面的 Pearson 相关分析结果所示 (图 13), 林下植被及其各组分的生物量与其自身的结构 参数关系最为紧密,而与林分特征因子间的关系大 多数并不显著。据此, 选取林下的灌木与草本的 7 个结构参数 $\left(D_{\mathrm{s}} 、 H_{\mathrm{s}} 、 C_{\mathrm{s}} 、 V_{\mathrm{s}} 、 H_{\mathrm{h}} 、 C_{\mathrm{h}} 、 V_{\mathrm{h}}\right)$ 作为预测变 量, 按照 5 种方程形式,分别拟合林下植被及其各组 分生物量的估算模型。

模型拟合发现,选用不同的预测变量及模型对 柏木林下灌木 $W_{\mathrm{s}}$ 及其器官 (叶 $W_{\mathrm{s} 1}$ 、枝茎 $W_{\mathrm{ss}}$ 地上 $W_{\mathrm{sa}}$ 和地下 $W_{\mathrm{sb}}$ ) 的估测效果差异大 (表 3 )。林下灌 木叶、枝茎、地上、地下和总的生物量的最佳估算模 型都是以 $H_{\mathrm{s}}$ 和 $C_{\mathrm{s}}$ 组合的参数 $V_{\mathrm{s}}$ 的幂函数形式, 分别 为 $W_{\mathrm{sl}}=0.0001 \times V_{\mathrm{s}}^{1.0268}\left(R_{\mathrm{a}}^{2}=0.760, P<0.001\right) 、 W_{\mathrm{ss}}=$ $0.0001 \times V_{\mathrm{s}}^{1.1593}\left(R_{\mathrm{a}}^{2}=0.754, P<0.001\right) 、 W_{\mathrm{sa}}=0.0001 \times$ $V_{\mathrm{s}}^{1.1171}\left(R_{\mathrm{a}}^{2}=0.784, P<0.001\right) 、 W_{\mathrm{sb}}=0.0003 \times V_{\mathrm{s}}^{0.9578}\left(R_{\mathrm{a}}^{2}=\right.$ $0.651, P<0.001)$ 和 $W_{\mathrm{s}}=0.0005 \times V_{\mathrm{s}}^{1.0411}\left(R_{\mathrm{a}}^{2}=0.762, P<\right.$ 
$0.001)$
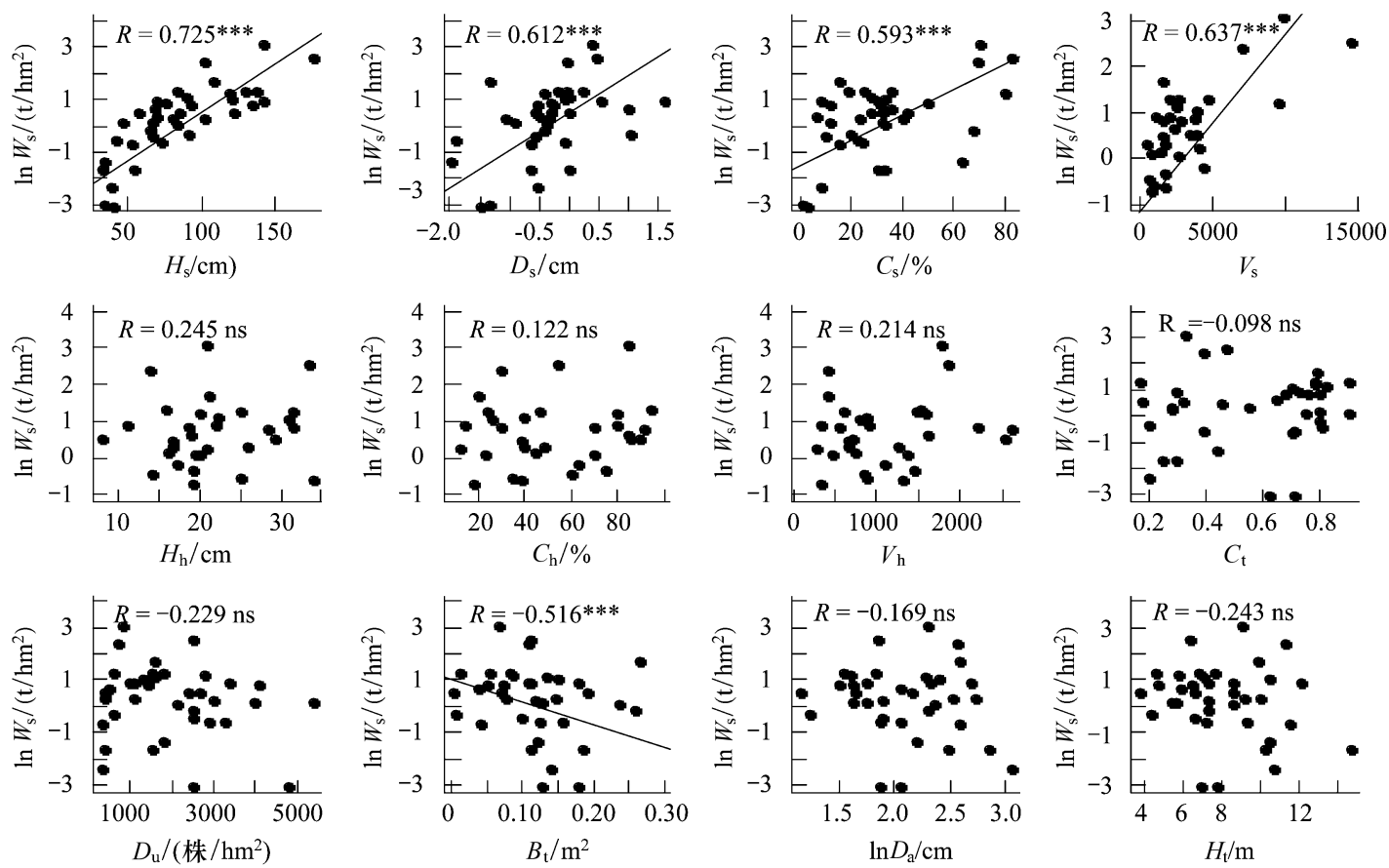

图 2 四川柏木林林下灌木生物量 $\left(W_{\mathrm{s}}\right)$ 与上层乔木和自身结构参数的相关关系

Fig.2 Correlations between the shrub biomass and structural parameters of overstory and understory by Pearson's correlation under the Cupressus funebris plantation forests in Sichuan Basin
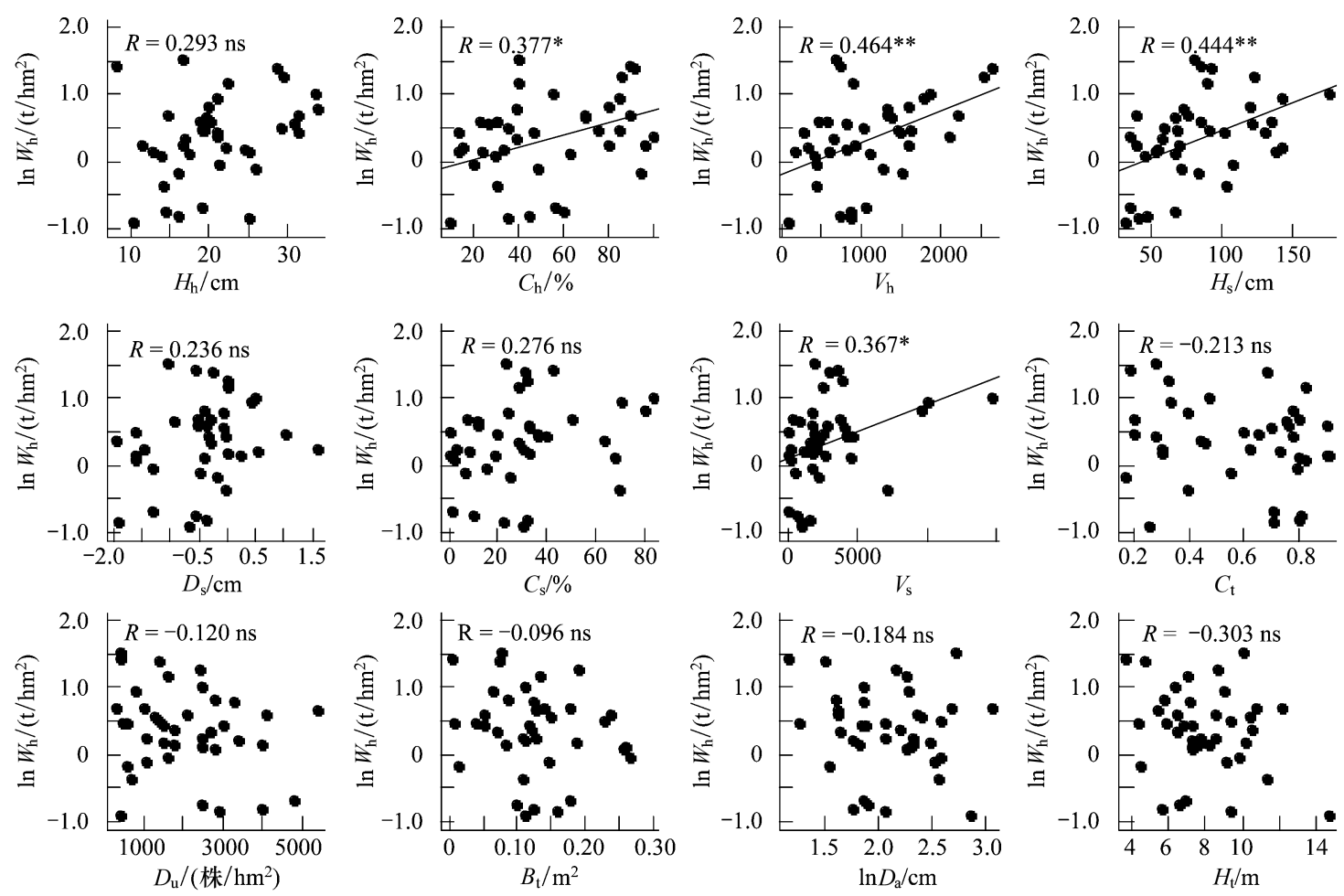

图 3 四川柏木林林下草本生物量 $\left(W_{\mathrm{h}}\right)$ 与上层乔木和自身结构的相关关系

Fig.3 Correlations between the herbaceous biomass and structural parameters of overstory and understory by Pearson's correlation under the Cupressus funebris plantation forests in Sichuan Basin 
表 3 四川柏木林林下植被总体及各部位生物量估算的最佳模型

Table 3 The optimal mixed- models to estimate the understory biomass and its components under the Cupressus funebris plantation from Sichuan

\begin{tabular}{|c|c|c|c|c|c|c|c|c|}
\hline \multirow{2}{*}{$\begin{array}{l}\text { 层次 } \\
\text { Layer }\end{array}$} & \multirow{2}{*}{$\begin{array}{c}\text { 部位 } \\
\text { Components }\end{array}$} & \multirow{2}{*}{$\begin{array}{l}\text { 模型 } \\
\text { Model }\end{array}$} & \multicolumn{3}{|c|}{ 系数 Coefficients } & \multirow{2}{*}{$R_{\mathrm{a}}^{2}$} & \multirow{2}{*}{ SEE } & \multirow{2}{*}{$F$} \\
\hline & & & $a$ & $b$ & $c$ & & & \\
\hline \multirow[t]{5}{*}{ 灌木 Shrub } & 叶 & $W_{\mathrm{sl}}=a \times V_{\mathrm{s}}^{b}$ & 0.0001 & 1.0268 & & 0.760 & 0.886 & $124.19^{* * * *}$ \\
\hline & 枝茎 & $W_{\mathrm{ss}}=a \times V_{\mathrm{s}}^{b}$ & 0.0001 & 1.1593 & & 0.754 & 1.016 & $120.60^{* * *}$ \\
\hline & 地上 & $W_{\mathrm{sa}}=a \times V_{\mathrm{s}}^{b}$ & 0.0001 & 1.1171 & & 0.784 & 0.900 & $142.59^{* * *}$ \\
\hline & 地下 & $W_{\mathrm{sb}}=a \times V_{b} s$ & 0.0003 & 0.9578 & & 0.651 & 1.072 & $73.87^{* * *}$ \\
\hline & 总体 & $W_{\mathrm{s}}=a \times V_{\mathrm{s}}^{b}$ & 0.0005 & 1.0411 & & 0.762 & 0.892 & $125.96^{* * * *}$ \\
\hline \multirow[t]{2}{*}{ 草本 Herb } & 地上 & $\ln W_{\mathrm{ha}}=a+b H_{\mathrm{h}}+c C_{\mathrm{h}}$ & -1.9656 & 0.0337 & 0.0149 & 0.410 & 0.534 & $14.55^{* * * *}$ \\
\hline & 总体 & $\ln W_{\mathrm{h}}=a+b H_{\mathrm{h}}+c C_{\mathrm{h}}$ & -0.8429 & 0.0322 & 0.0094 & 0.201 & 0.599 & $5.90 * *$ \\
\hline 林下植被 & 地上 & $\ln W_{\text {ua }}=a+b H_{\mathrm{s}}+c C_{\mathrm{s}}$ & -1.2839 & 0.0151 & 0.0151 & 0.700 & 0.484 & $46.52^{* * * *}$ \\
\hline \multirow[t]{2}{*}{ Understory } & 地下 & $\ln W_{\mathrm{ub}}=a+b H_{\mathrm{s}}+c C_{\mathrm{s}}$ & -1.2714 & 0.0166 & 0.0069 & 0.538 & 0.614 & $23.70^{* * * *}$ \\
\hline & 总体 & $\ln W_{\mathrm{u}}=a+b H_{\mathrm{s}}+c C_{\mathrm{s}}$ & -0.5358 & 0.0158 & 0.0111 & 0.695 & 0.463 & $45.51^{* * *}$ \\
\hline
\end{tabular}

$R_{\mathrm{a}}^{2}$, 调整的决定系数 adjusted R-square; $W_{\mathrm{sl}}$, 灌木叶生物量 leaf biomass for shrubs; $W_{\mathrm{ss}}$, 灌木枝茎生物量 stem and branch biomass for shrubs; $W_{\mathrm{sa}}$, 灌木地上生物量 aboveground biomass for shrubs; $W_{\mathrm{sb}}$, 灌木地下生物量 belowground biomass for shrubs; $W_{\mathrm{s}}$, 灌木总生物量 total shrubs biomass; $H_{\mathrm{s}}$, 灌 木均高 average shrub height; $C_{\mathrm{s}}$, 灌木盖度 shrub cover; $V_{\mathrm{s}}$, 灌木体积 $\left(V_{\mathrm{s}}=H_{\mathrm{s}} \times C_{\mathrm{s}}\right)$ shrub volume $\left(V_{\mathrm{s}}=H_{\mathrm{s}} \times C_{\mathrm{s}}\right)$; $W_{\mathrm{ha}}$, 林下草本地上生物量 aboveground biomass for herbs; $W_{\mathrm{h}}$, 林下草本总生物量 total herbs biomass; $H_{\mathrm{h}}$, 草本均高 average herb height; $C_{\mathrm{h}}$, 草本盖度 herb cover; $W_{\text {ua }}$, 林下植被地上生物量 aboveground biomass for understoy; $W_{\mathrm{ub}}$, 林下植被地下生物量 belowground biomass for understory; $W_{\mathrm{u}}$, 林下植被总生物量 total understory biomass; SEE: 模型的估计误差 standard error of the estimate; **,P<0.01;***,P<0.001

在草本生物量的拟合中发现,使用草本的均高 $\left(H_{\mathrm{h}}\right)$ 、盖度 $\left(C_{\mathrm{h}}\right)$ 和体积 $\left(V_{\mathrm{h}}\right)$ 进行拟合, 虽然通过了 显著性检验, 但模型精度都较低 $\left(R_{\mathrm{a}}^{2}<0.410, P<\right.$ 0.01 , 表 3$)$ 。林下草本总生物量的最佳估算模型为 多元线性方程 $\ln W_{\mathrm{h}}=a+b H_{\mathrm{h}}+c C_{\mathrm{h}}$, 但估算精度较低 $\left(R_{\mathrm{a}}^{2}=0.201, P=0.006\right)$; 最佳估算林下草本地上生物 量的模型同为多元线性方程 $\ln W_{\mathrm{ha}}=a+b H_{\mathrm{h}}+c C_{\mathrm{h}}$, 模 型精度也不高 $\left(R_{\mathrm{a}}^{2}=0.410, P<0.001\right)$ 。特别指出的 是,在构建林下草本地下生物量估算模型中发现, 草 本的均高 $\left(H_{\mathrm{h}}\right)$ 、盖度 $\left(C_{\mathrm{h}}\right)$ 和体积 $\left(V_{\mathrm{h}}\right)$ 等指标在 5 种 不同模型构建中, 均未能通过显著性检验 $(P>$ $0.05)$ 。

进一步在拟合建立林下植被总生物量估算模型 中发现,使用灌木 $H_{\mathrm{s}} 、 C_{\mathrm{s}}$ 和 $V_{\mathrm{s}}$ 去估算 $W_{\mathrm{s}}$ 获得了较好
的估算精度 (表 3 )。估算林下植被地上 $\left(R_{\mathrm{a}}^{2}=\right.$ $0.700, P<0.001)$ 、地下 $\left(R_{\mathrm{a}}^{2}=0.538, P<0.001\right)$ 和总体 生物量 $\left(R_{\mathrm{a}}^{2}=0.695, P<0.001\right)$ 的最佳模型形式均为 多元线性方程 $\ln \mathrm{W}=a+b H_{\mathrm{s}}+c C_{\mathrm{s}}$ 。而林下草本体积 $V_{\mathrm{h}}$ 在模型拟合中贡献较小 $\left(R_{\mathrm{a}}^{2}=0.088, P=0.04\right)$, 草 本 $H_{\mathrm{h}}$ 和 $C_{\mathrm{h}}$ 在模型拟合中无法通过显著性检验 $(P>$ $0.05)$ 。

逐步回归分析发现,采用林分密度 $\left(D_{\mathrm{u}}\right)$ 、灌木均 高 $\left(H_{\mathrm{s}}\right)$ 和灌木盖度 $\left(C_{\mathrm{s}}\right)$ 预测林下植被生物量获得 了较高的估算精度 (表 4)。与前述多元模型相比, 林分密度 $D_{\mathrm{u}}$ 的加人使得林下植被地上 $\left(R_{\mathrm{a}}^{2}=0.732\right.$, $P<0.001)$ 、地下 $\left(R_{\mathrm{a}}^{2}=0.558, P<0.001\right)$ 及总生物量 $\left(R_{\mathrm{a}}^{2}=0.721, P<0.001\right)$ 估算模型的精度得到有效提 高 $\left(R_{\mathrm{a}}^{2}\right.$ 增大)。

\section{表 4 四川柏木林下植被生物量逐步回归模型}

Table 4 Stepwise regression model of understory biomass under Cupressus funebris plantation in Sichuan basin

\begin{tabular}{|c|c|c|c|c|c|c|c|c|c|}
\hline \multirow{2}{*}{$\begin{array}{l}\text { 部位 } \\
\text { Components }\end{array}$} & \multirow{2}{*}{$\begin{array}{l}\text { 模型 } \\
\text { Model }\end{array}$} & \multicolumn{4}{|c|}{ 系数 Coefficients } & \multirow{2}{*}{$R_{\mathrm{a}}^{2}$} & \multirow{2}{*}{ SEE } & \multirow{2}{*}{$F$} & \multirow{2}{*}{ AIC } \\
\hline & & $a$ & $b$ & $c$ & $d$ & & & & \\
\hline 地上 $W_{\text {uа }}$ & $\ln W_{\text {uа }}=a+b D_{\text {u }}+c H_{\mathrm{s}}+d C_{\mathrm{s}}$ & -0.9894 & -0.0001 & 0.0155 & 0.0131 & 0.732 & 0.457 & $36.59^{\text {**** }}$ & 60.85 \\
\hline 地下 $W_{\mathrm{ub}}$ & $\ln W_{\mathrm{ub}}=a+b D_{\mathrm{u}}+c H_{\mathrm{s}}$ & -0.9153 & -0.0001 & 0.0182 & & 0.558 & 0.601 & $25.57^{* * *}$ & 84.13 \\
\hline 总体 $W_{\mathrm{u}}$ & $\ln W_{\mathrm{u}}=a+b D_{\mathrm{u}}+c H_{\mathrm{s}}+d C_{\mathrm{s}}$ & -0.2813 & -0.0001 & 0.0161 & 0.0094 & 0.721 & 0.443 & $34.53^{* * *}$ & 59.22 \\
\hline
\end{tabular}

$R_{\mathrm{a}}^{2}$ : 调整的决定系数; $W_{\mathrm{ua}}$ : 林下植被地上生物量; $W_{\mathrm{ub}}$ : 林下植被地下生物量; $W_{\mathrm{u}}$ : 林下植被总生物量 $H_{\mathrm{s}}$ : 灌木均高; $D_{\mathrm{u}}$ : 林分密度; $C_{\mathrm{s}}$ : 灌 木盖度;SEE:模型的估计误差; AIC:赤池信息量准则; $* * * P<0.001$ 


\section{4 讨论与结论}

4.1 四川东部柏木林林下生物量与结构的关系

林下植被盖度、高度、体积等结构参数与林下生 物量相关关系突出 ${ }^{[34]}$, 因而常作为林下植被生物量 模型构建的基本预测变量使用 ${ }^{[9,35]}$ 。研究结果表 明, 林下植被生物量跟灌木层片结构参数相关更明 显 (图 1), 但与草本层片结构参数并不相关。进一 步发现, 林下植被生物量与灌木平均高度的关系更 为紧密, 而不是灌木盖度与密度。这表明森林中林 下灌木群体平均高度及体积能够更好反映林下灌木 对林下异质性资源环境空间的生态适应能力, 因为 在林下更高的灌木生长意味着可更有效的获取限制 性光资源 ${ }^{[2]}$ 。但是, 林下灌木生物量与其结构参数 的关联程度与纯粹的灌丛是明显不同的 ${ }^{[10,36-38]}$, 这 应该归因于两类环境中限制性资源类型、程度以及 在不同的资源生态位下灌木形态性状的权衡关系可 塑性的明显差异。一般缺乏森林林冠抑制作用下的 灌木生长, 通过分枝和萌蓝向水平空间拓展是明显 的,因此其冠幅或冠直径及分枝程度可更好指示资 源利用能力与生物量累积 ${ }^{[36,39-40]}$ 。

林下植被生物量与林分郁闭度、密度、胸高断面 积等参数关系紧密, 因为这些参数综合反映着林分 拥挤程度,控制着林内光资源格局,这对林下植被的 生长、生物量积累造成直接影响 ${ }^{[14-15,41]}$ 。但是, 单独 使用各因子进行相关分析时,本研究没有发现存在 明确的相关关系。这可能受到林分年龄的严重影 响 ${ }^{[16,42]}$, 因为林龄反应出森林发育程度与环境的稳 定性,能够一定程度上指示林分透光状况,处于不同 年龄阶段的群落树种组成、冠型等都会改变林下的 光环境, 从而影响林下植被的盖度与生物量 ${ }^{[2,7]}$ 。 干扰的影响也是不能排除的,林下植被对干扰的影 响最为敏感 ${ }^{[43]}$ 。研究区内的柏木林大多是荒山荒 坡造林形成的,位于村庄周围, 被农田包围,已成为 农户承包山林, 深受林下放牧、灌草收割积肥、及偷 伐自用材等活动干扰, 虽然调查时尽量排除这种有 明显影响痕迹的林分, 但这种干扰对林下植被生物 量的影响不容忽视。Ares 等 ${ }^{[13]}$ 的研究就发现, 疏伐 可显著促进林下植被变化, 改变林分结构与下木层 的生产能力。因此, 深入揭示林分结构调整及林下 植被管理对林下生物量与林分结构特征因子关系的
影响还需进一步研究。

\section{2 柏木林下植被生物量模型}

本研究发现, 柏木人工林林下灌木群体生物量 优化混合模型是以体积 $V_{\mathrm{s}}$ 为变量的幂函数方程 $W=$ $a \times V_{s}^{b}$, 比单一采用平均高、基径或盖度的精度更高， 表明在柏木这样塔型的单优势种组成的林分环境 中, 灌木群体的性状关系复杂, 性状权衡关系存在较 大可塑性,采用综合指标能反映其资源利用生态位 的复合性状,因而可获得更好估测效果。本文的研 究结果与黎燕琼等 ${ }^{[25]}$ 针对柏木人工林林下优势灌 木黄荆建立的单种模型是不同的,柏木人工林林下 优势灌木黄荆的最佳单种模型为以基径为参数建立 的二次或三次曲线方程, 其单种模型的估算精度 $\left(R^{2}=0.906\right)$ 稍高于本研究的混合模型 $\left(R_{\mathrm{a}}^{2}=\right.$ $0.762)$, 显然与本研究的大区域的空间异质性取样 相关, 因为植物性状权衡关系深受资源供给程度影 响,而表现出对资源利用的可塑性差异。在混合模 型构建中,群体基径仅对灌木枝生物量估算效果较 好, 相反, 平均高度、盖度、体积在混合模型构建中获 得了较为理想的估算效果 ${ }^{[8,37]}$, 这主要是由于灌木 多分枝现象, 致使基径并不充分指示灌木形 态 $^{[36,44]}$ 。Sah 等 ${ }^{[44]}$ 也指出, 对于多分枝的灌木, 把 每个分枝当作一个个体对待, 能够提高模型的精度。

在柏木人工林林下草本层混合模型构建中,使 用高度、盖度、体积等因子及其组合去建立估算模型 都未能获得较好的估算精度 $\left(R_{\mathrm{a}}^{2}<0.410, P<0.01\right)$ ， 尤其是草本地下生物量估算模型未能通过显著性检 验 $(P>0.05)$, 这明显跟前述的林下灌木不同。这 可能与冠层覆盖下林下草本群体的形态变异紧密相 关, 因为草本的形态直接影响着草本的盖度、高度、 体积等属性变异, 对草本层各因子的测算带来不确 定性 ${ }^{[34,45]}$ 。MacDonald 等 $^{[35]}$ 充分考虑草本植物形 态, 把草本植物细分为高草、矮草、禾草和非禾草几 个功能群组, 分别构建了草本植物不同功能群生物 量的混合模型, 就获得了较高的估算精度 $\left(R^{2}>\right.$ 0.81 ), 为推测提供了佐证。另外, 由于草本植物的 盖度和生物量受到生长季的影响较为严重, 不同生 长季和不同年份之间其估算模型都不同 ${ }^{[15]}$, 致使草 本植物生物量模型的构建带来困难 ${ }^{[46]}$ 。

针对林下植被总生物量的优化估算模型为多元 线性模型 $\ln W_{\mathrm{u}}=a+b H_{\mathrm{s}}+c C_{\mathrm{s}}$ (表 3), 而在逐步回归中 
加人林分密度后, 林下植被各部分生物量 (地上、地 下部分) 的模型精度都有所提高 (表 5), 表明冠层结 构显著左右着林下环境资源时空异质性,制约着林 下生物量和生产量。各种模型中,使用多个因子参 与拟合比单个因子作为参数的模型有更好的估算效 果 ${ }^{[22,38,40]}$ 。但是, 如单独使用林分密度、郁闭度、胸 高断面积等林分立地特征因子进行模型拟合时,模 型未能通过显著性检验 $(P>0.05$; 图 1一图 3$)$ 。这 说明在林下植被生物量模型构建中, 林下植被自身 结构参数比林分特征因子更适用于其生物量模型构 建,而林分因子是通过左右林下资源环境制约林下 植被结构性状而间接去影响林下植被发育与生物量 积累的 ${ }^{[7]}$ 。

不同模型之间其适用范围有所不同。已有研究 发现, 单种模型比起混合模型有更高的估算精

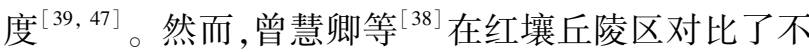
同林下物种生物量的单种模型和混合模型,发现白 栋( Rhododendron simsii)、山莓 (Rubus corchorifolius) 和乌饭树 (Vaccinium bracteatum) 等树种的混合模型 优于单种模型。在区域生物量估算中, 无法对每一 物种进行单种模型构建, 使用混合模型比单种模型 更高效、简便,在精度允许的情况下可作为区域林下 植被生物量估算的首选方法。

总体来看, 本研究揭示了四川柏木人工林林下 生物量与林分结构的关系, 发展了有效的柏木林下 植被生物量与灌木生物量有效估测模型, 为四川柏 木林林下生物量估算与碳计量体系提供了依据。但 依据调查获得的 40 个林下植被生物量数据建立估 测模型, 数据偏少, 增加更多的数据进行更全面的数 据拟合是必要的。此外,由于林下植被生物量受到 多种因素影响,在应用各个混合模型前,进一步开展 模型验证也是必要的。

致谢: 参加野外调查的还有杜忠、方志强、刘金、王 菬、赵庆霞、冯德枫以及四川农业大学暑期实习学 生; 调查过程中承蒙四川省林勘院张文、赖长鸿、张 炎周等及巴中、南充、广元、绵阳等相关市、县林业局 的支持和帮助,特此致谢。

\section{References :}

[ 1 ] Nilsson M C, Wardle D A. Understory vegetation as a forest ecosystem driver: evidence from the northern Swedish boreal forest. Frontiers in Ecology and the Environment, 2005, 3(8): 421- 428 .

[ 2 ] Wagner S, Fischer H, Huth F. Canopy effects on vegetation caused by harvesting and regeneration treatments. European Journal of Forest Research, 2011, 130(1) : 17-40.

[ 3 ] Brockerhoff E G, Jactel H, Parrotta J A, Quine C P, Sayer J. Plantation forests and biodiversity: oxymoron or opportunity? Biodiversity and Conservation, 2008, 17(5) : 925-951.

[ 4 ] Bremer L, Farley K. Does plantation forestry restore biodiversity or create green deserts? A synthesis of the effects of land-use transitions on plant species richness. Biodiversity and Conservation, 2010, 19(14) : 3893-3915.

[ 5 ] Schmiedinger A, Kreyling J, Steinbauer M J, Macdonald S E, Jentsch A, Beierkuhnlein C. A continental comparison indicates long-term effects of forest management on understory diversity in coniferous forests. Canadian Journal of Forest Research, 2012, 42 (7) : 1239-1252

[ 6 ] Gonzalez M, Augusto L, Gallet-Budynek A, Xue J M, YauschewRaguenes N, Guyon D, Trichet P, Delerue F, Niollet S, Andreasson F, Achat D L, Bakker M R. Contribution of understory species to total ecosystem aboveground and belowground biomass in temperate Pinus pinaster Ait. forests. Forest Ecology and Management, 2013, 289: 38-47.

[ 7 ] Strong W L. Tree canopy effects on understory species abundance in high-latitude Populus tremuloides stands, Yukon, Canada. Community Ecology, 2011, 12(1) : 89-98.

[ 8 ] Brown J K. Estimating shrub biomass from basal stem diameters. Canadian Journal of Forest Research, 1976, 6(2) : 153-158.

[ 9 ] Röttgermann M, Steinlein T, Beyschlag W, Dietz H. Linear relationships between aboveground biomass and plant cover in low open herbaceous vegetation. Journal of Vegetation Science, 2000, $11(1): 145-148$.

[10] Liu X L, Hao X D, Yang D S, Liu S R, Su Y M, Cai X H, He F, Ma Q Y. Aboveground biomass and its models of Quercus aquifolioides thicket community in Balangshan Mountain in Wolong Natural Reserve. Chinese Journal of Ecology, 2006, 25 ( 5 ) : 487-491.

[11] Li G T, Qing F C, Jia S Y, Dong J L, Jirgele, Wang M G. Study on biomass estimation models of xerophyte shrub. Journal of Inner Mongolia Forestry College, 1998, 20(2): 24-31.

[12] Pieper R D. Overstory-understory relations in pinyon-juniper woodlands in New Mexico. Journal of Range Management, 1990 , $43(5)$ : 413-415.

[13] Ares A, Neill A R, Puettmann K J. Understory abundance, species diversity and functional attribute response to thinning in coniferous stands. Forest Ecology and Management, 2010, 260 (7) : 1104-1113.

[14] Mitchell J E, Popovich S J. Effectiveness of basal area for estimating canopy cover of ponderosa pine. Forest Ecology and Management, 1997, 95(1): 45-51. 
[15] González-Hernández M P, Silva-Pando F J, Jiménez M C. Production patterns of understory layers in several Galician ( NW Spain) woodlands: Seasonality, net productivity and renewal rates. Forest Ecology and Management, 1998, 109 ( 1/3): 251-259.

[16] Zhang W P, Huang J C, Li X B. Analysis of influencing factors of undergrowth biomass in Cunninghamia lanceolata plantations. Journal of Fujian Forestry Science and Technology, 2007, 34 (3) : 97-99, 149-149.

[17] Zheng S W, Tang M, Zou J H, Mu C L. Summary of research on shrub biomass in China. Journal of Chengdu University: Natural Sciences, 2007, 26(3): 189-192.

[18] Wu P F, Zhu B, Liu S R, Wang X G. Carbon storage and its allocation in mixed alder-cypress plantations at different age stages. Chinese Journal of Applied Ecology, 2008, 19 ( 7 ): 1419- 1424

[19] Zhu Y E, Yao D M. A study on the development and biomass of undergrowth vegetations in Cupressus funebris plantations in Yichang Suburbs. Forest Resources Management, 2007, (2): 52-56.

[20] Wang J. Community characteristics and its biomass in alder and cypress mixed young forest. Journal of Sichuan Forestry Science and Technology, 1993, 14(1): 66-69.

[21] Liu X L, Yan W X, Xiang C H, Jiang J M. Biomass and biomass models of secondary subtropical vegetation in Tuojiang river valley. Acta Phytoecologica Sinica, 1997, 21(5): 441-454.

[22] Zeng Z Y, Liu Q J, Zeng H Q. Study of biomass models of some kinds of shrubs in Qianyanzhou, Jiangxi province. Journal of Fujian Forestry Science and Technology, 2005, 32(4) : 68-72.

[23] Dickinson Y L, Zenner E K. Allometric equations for the aboveground biomass of selected common eastern hardwood understory species. Northern Journal of Applied Forestry, 2010, $27(4)$ : 160-165.

[24] Zeng H Q, Liu Q J, Feng Z W, Ma Z Q. Biomass equations for four shrub species in subtropical China. Journal of Forest Research, 2009, 15(2): 83-90.

[25] Li Y Q, Zheng S W, Gong G T, Chen J H, Tang B, Zhu Z F, Wu X X, Mu C L. Biomass and its allocation of undergrowth Vitex negundo L. in different age classes of mixed cypress forest. Acta Ecologica Sinica, 2010, 30(11) : 2809-2818.

[26] Xiang C H, Luo Z S, Chen J H, He F, Luo X H. Research on characteristics of community structure of the main forests in hilly regions of the Sichuan basin. Journal of Sichuan Forestry Science and Technology, 2005, 26(5) : 25-29.

[27] Zheng S W, Niu M, Zhang Q, Li Y Q, Mu C L, Gong G T, Chen J H, Zhu Z F, Wu X X. A study of the vegetation community structure and biodiversity of different Cupressus funebris types in hilly areas of central Sichuan province. Journal of Sichuan Forestry Science and Technology, 2011, 32(5) : 20-28.

[28] Li R W. Researches on Construction and Management of
Protection Forest System in Upper Reach of Yangtze River. Chengdu: Sichuan Science and Technology Press, 2004.

[29] Porté A J, Samalens J C, Dulhoste R, Teissier Du Cros R, Bosc A, Meredieu C. Using cover measurements to estimate aboveground understorey biomass in Maritime pine stands. Annals of Forest Science, 2009, 66(3) : 307-307.

[30] Lu Z L, Gong X S. Progress on the research of shrub biomass estimation. Forest Inventory and Planning, 2009, 34(4) : 37-40, $45-45$.

[31] Zar J H. Biostatistical Analysis. 4th ed. New Jersey: Prentice Hall, 1999: 419-424.

[32] Hurvich C M, Tsai C L. Regression and time series model selection in small samples. Biometrika, 1989, 76(2): 297-307.

[33] R Development Core Team. R: A Language and Environment for Statistical Computing. R Foundation for Statistical Computing, Vienna, Austria, 2012. http://www.R-project.org/.

[34] Wayne E R, Van Auken O W. Herbaceous cover and biomass of carex planostachys in Juniperus ashei woodlands of central texas. The Southwestern Naturalist, 2010, 55(3) : 434-441.

[35] MacDonald R L, Burke J M, Chen H Y H, Prepas E E. Relationship between aboveground biomass and percent cover of ground vegetation in Canadian boreal plain riparian forests. Forest Science, 2012, 58(1): 47-53.

[36] Sun S C, Qian N B. Path analysis of morphological parameters of Convolvulus tragacuthoiedes population and individual biomass modeling of subshrubs. Chinese Journal of Applied Ecology, $1999,10(02): 155-158$.

[37] Zeng H Q, Liu Q J, Ma Z Q, Zeng Z Y. The regression model of Loropetalum chinense biomass based on canopy diameter and plant height. Journal of Nanjing Forestry University: Natural Science, 2006, 30(4) : 101-104.

[38 ] Zeng H Q, Liu Q J, Feng Z W, Ma Z Q, Hu L L. Estimation models of understory shrub biomass and their applications in red soil hilly region. Chinese Journal of Applied Ecology, 2007, 18 (10) : 2185-2190.

[39] Návar J, Nájera J, Jurado E. Biomass estimation equations in the Tamaulipan thornscrub of north-eastern Mexico. Journal of Arid Environments, 2002, 52(2) : 167-179.

[40 ] Wang L, Zhang H, Hasi, Zheng Q H, Liu L Y. A study on the estimating method of shrub upper biomass based on the crown diameter and plant height. Journal of Beijing Normal University: Natural Science, 2004, 40(05) : 700-704.

[41] Peek J M, Korol J J, Gay D, Hershey T. Overstory-understory biomass changes over a 35-year period in southcentral Oregon. Forest Ecology and Management, 2001, 150(3) : 267-277.

[42] Pan P, Mu C C, Sun Z H. Biomass of shrub and herb layers in Larix olgensis plantations. Journal of Northeast Forestry University, $2007,35(04): 1-2,6-6$.

[43] Hart S A, Chen H Y H. Understory vegetation dynamics of north american boreal forests. Critical Reviews in Plant Sciences, 2006, 


\title{
生境不完全重叠的两种鲤科鱼类耐低氧 及运动能力比较
}

\author{
张安杰, 曹振东, 付世建 ${ }^{*}$ \\ (重庆师范大学, 进化生理与行为学实验室,动物生物学重庆市重点实验室, 重庆 401331)
}

\begin{abstract}
摘要: 以乌江流域亲缘关系近,但分布并不完全重叠的马口鱼 (Opsariichthys bidens) 和宽鳀鱲 (Zacco platypus) 作为实验对象, 分别考察这两种实验鱼的低氧耐受及游泳运动能力。将野外采回的实验鱼置于 $(25 \pm 1)^{\circ} \mathrm{C}$ 条件下, 分别测定两种鱼的临界氧分 压 $\left(P_{\mathrm{crit}}\right)$ 、水面呼吸 $(A S R)$ 、失去平衡点 $(L O E)$ 以及在不同溶氧水平 $(8.0 、 4.0$ 和 $2.0 \mathrm{mg} / \mathrm{L})$ 下的临界游泳速度 $\left(U_{\mathrm{crit}}\right)$ 和活跃 耗氧率 $\left(M O_{\text {2active }}\right)$ 。研究发现: 马口鱼的 $P_{\text {crit }}(2.44 \pm 0.20) \mathrm{mg} / \mathrm{L}$ 显著高于宽魦鱲 $(1.86 \pm 0.10) \mathrm{mg} / \mathrm{L}(P=0.031)$ 。但马口鱼的 $50 \% \operatorname{ASR}(1.23 \pm 0.16) \mathrm{mg} / \mathrm{L}$ 显著低于宽鯺鱲 $(1.97 \pm 0.11) \mathrm{mg} / \mathrm{L}(P=0.023)$; 马口鱼的 $50 \%$ LOE $(0.84 \pm 0.01) \mathrm{mg} / \mathrm{L}$ 同样显著 低于宽鯺鱲 $(0.97 \pm 0.02) \mathrm{mg} / \mathrm{L}(P=0.004)$ 。宽鳍鱲在 8.0 和 $4.0 \mathrm{mg} / \mathrm{L}$ 下的游泳能力显著高于马口鱼, 然而马口鱼和宽鳍鱲的 $U_{\text {crit }}$ 均随测定溶氧水平的下降而显著降低 $(P<0.01)$; 宽鯺鱲和马口鱼的运动耗氧率均随水流速度的增加而呈现指数增加, 但

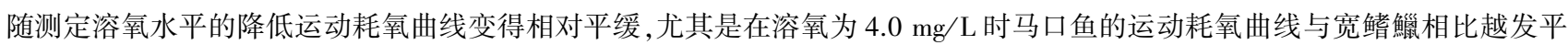
缓; 两种实验鱼的 $M O_{2 a c t i v e}$ 随溶氧水平下降的变化趋势与 $U_{\text {crit }}$ 相似 $(P<0.001)$ 。结果表明:两种野外生存的实验鱼不仅在低氧耐 受能力方面存在显著差异, 而且两者的游泳运动能力也有不同表现, 这很有可能与其遗传特征、生存环境及生态习性相关。
\end{abstract}

关键词: 宽鳍鱲; 马口鱼; 水面呼吸; 临界氧分压; 失去平衡点; 临界游泳速度

\section{Comparison of hypoxia tolerance and locomotor performance in two cyprinids with incompletely overlapped habitat}

ZHANG Anjie, CAO Zhendong, FU Shijian *

Laboratory of Evolutionary Physiology and Behaviour, Chongqing Key Laboratory of Animal Biology, Chongqing Normal University, Chongqing 401331, China

\begin{abstract}
Two genetic closely related cyprinids-hook snout carp (Opsariichthys bidens) and pale chub (Zacco platypus) with incompletely overlapped habitats in $\mathrm{Wu}$ River-were selected as experimental models to investigated the difference of hypoxia tolerance and locomotor performance between two fish species and whether the possible exist difference be related with the distributed habitats. We first measured the critical oxygen tension $\left(P_{\text {crit }}\right)$, aquatic surface respiration $(A S R)$ and loss of equilibrium ( $L O E)$ as the hypoxia indicators. Then we measured the critical swimming speed $\left(U_{\text {crit }}\right)$ and active oxygen consumption rate $\left(M O_{\text {2active }}\right)$ at different dissolved oxygen level $(8.0,4.0$ and $2.0 \mathrm{mg} / \mathrm{L}$, respectively $)$ at $(25.0 \pm$ $1.0){ }^{\circ} \mathrm{C}$. The $P_{\text {erit }}$ of hook snout carp $(2.44 \pm 0.20) \mathrm{mg} / \mathrm{L}$ were significantly higher than that of pale chub $(1.86 \pm 0.10) \mathrm{mg} /$ L $(P=0.031)$. However, the dissolved oxygen level at which 50\% fish performing ASR $(P=0.023)$ and LOE $(P=0.004)$ in hook snout carp $(A S R:(1.23 \pm 0.16) \mathrm{mg} / \mathrm{L} ; L O E:(0.84 \pm 0.01) \mathrm{mg} / \mathrm{L})$ were significantly lower than those in pale chub $(A S R:(1.97 \pm 0.11) \mathrm{mg} / \mathrm{L} ; L O E:(0.97 \pm 0.02) \mathrm{mg} / \mathrm{L})$. Both the $U_{\text {crit }}$ and $M O_{\text {2active }}$ of hook snout carp and pale chub
\end{abstract}

基金项目: 国家自然科学基金项目(31172096); 重庆科技创新能力建设项目(CSTC2010CA1010)

收稿日期: 2013-01-23; 网络出版日期: 2014-03-11

* 通讯作者 Corresponding author.E-mail: shijianfu9@ hotmail.com 